\title{
Thermal Annealing and Laser Treatment of Sol-gel Derived Zirconia Thin Films
}

\author{
Rainer Jahn ${ }^{1}$ - Sönke Steenhusen ${ }^{1} \cdot$ Peer Löbmann ${ }^{1}$
}

Accepted: 24 April 2020 / Published online: 6 May 2020

(C) The Author(s) 2020

\begin{abstract}
Soluble precursor powders were prepared from zirconium propoxide and acetylacetone by evaporation of volatile products directly after the hydrolysis step. Dissolution of the solid residue resulted in solutions that were further processed by dip coating on glass substrates. One set of asdried films was thermally annealed in an oven at temperatures between 300 and $600^{\circ} \mathrm{C}$. In parallel, samples were irradiated by a $\mathrm{CO}_{2}$ laser, in doing so laser power density and beam feed rate were varied. The thermally cured and laser treated film series were characterized with respect to film thickness, refractive index, phase content, crystallite size and film microstructure.
\end{abstract}

Keywords $\mathrm{ZrO}_{2}$. Thin films · Thermal curing · Laser processing · Microstructure

\section{Introduction}

The preparation of inorganic thin films by sol-gel processing has proven to be a flexible and cost-efficient alternative to vacuum-based technologies such as sputtering $[1,2]$. The development of wet-chemical coating solutions with a sufficient stability under industrial conditions, however, is a challenging task. In this context the use of soluble precursor powders has been established for film compositions ranging from $\mathrm{Al}_{2} \mathrm{O}_{3}$ [3], $\mathrm{TiO}_{2}$ [4], $\mathrm{ZrO}_{2}$ [5] to lead zirconate titanate (PZT) [6]. As usual for such inorganic compositions film densification and crystallization were performed by thermal annealing.

As an alternative to oven treatment, sol-gel derived films may be annealed by irradiation with a laser source. Different lasers such as $\operatorname{ArF}[7,8], \mathrm{KrF}$ [7, 9-14], HeCd $[15]$ and frequency tripled NdYAG $[16,17]$ operating at wavelengths below $1 \mu \mathrm{m}$ have been used. In these cases, selective energy transfer to the film material is assumed which may enable the use of polymer substrates that may not withstand thermal sintering above $150^{\circ} \mathrm{C}$. Even though this objective is commonly claimed, in most of

Peer Löbmann

peer.loebmann@isc.fraunhofer.de

1 Fraunhofer-Institut für Silicatforschung, Neunerplatz 2, 97082 Würzburg, Germany 
the above studies inorganic substrates were used. This is so because organic residues were removed from the films by thermal treatment up to $500^{\circ} \mathrm{C}$ before the final laser irradiation.

For sintering of sol-gel films on glass and silica substrates the use of $\mathrm{CO}_{2}$ lasers with a wavelength of $10,6 \mu \mathrm{m}$ has been reported [18-21]. As these glasses strongly absorb in this spectral range $[22,23]$, an indirect heating of the above sol-gel films can be assumed. The local temperatures may well exceed the respective softening point of the glass substrate. Therefore, crystal phases that are not accessible by oven treatment may become accessible [19, 24-26].

In a previous publication [27] we systematically compared the $\mathrm{CO}_{2}$ laser treatment of $\mathrm{TiO}_{2}$ films derived from soluble precursor powders to parallel thermal annealing experiments. Laser power density could well be correlated to furnace temperatures in terms of film thickness and refractive index. However, whereas conventional thermal heating resulted in the anatase phase, exclusively rutile was found in films after laser treatment. In this manuscript we extend these systematic investigations to sol-gel derived coatings of zirconia $\left(\mathrm{ZrO}_{2}\right)$ composition.

\section{Experimental Procedure}

\section{Film Preparation}

Soluble $\mathrm{ZrO}_{2}$ precursor powders were prepared similar to a procedure previously established for $\mathrm{TiO}_{2}$ [4, 27]: By slow addition of 103,5 g (1.0 mol) acetylacetone to 485,6 g (1.0 mol) zirconium (IV)-propoxide a clear honey yellow solution was obtained which was heated up to $80^{\circ} \mathrm{C}$ for one hour. Subsequently, $54.0 \mathrm{~g}(3.0 \mathrm{~mol})$ deionized water was added. Without any further delay all volatile components were separated from the reaction mixture by rotational evaporation at reduced pressure $(<40 \mathrm{mbar})$ with a maximum bath temperature of $80^{\circ} \mathrm{C}$.

The coating solution was prepared by dissolution of this amorphous precursor powder in a mixture of 90 mass \% ethanol and 10 mass \% 1,5-pentanediol to result in an oxide yield of 6 mass \% respective to crystalline $\mathrm{ZrO}_{2}$. After stirring for $12 \mathrm{~h}$ it was filtered through a $0.45 \mu \mathrm{m}$ membrane.

Thin films were deposited by dip coating of borosilicate glass (Schott, Borofloat ${ }^{\circledR}$, $3.3 * 100 * 100 \mathrm{~mm}^{3}$ ) that was pre-cleaned in a laboratory dishwasher using an alkaline detergent. Coating experiments were performed within $8 \mathrm{~h}$ after cleaning. Directly before film deposition the substrates were additionally cleaned with compressed air.

Thin film preparation was carried out in clean room atmosphere at $24^{\circ} \mathrm{C}$. The coating was made with a withdrawal rate resulting in a film thickness of $120 \mathrm{~nm}$ after sintering at $600^{\circ} \mathrm{C}$. The as-coated plates remained in a fume hood for at least two minutes before they were dried in a vented furnace at $80^{\circ} \mathrm{C}$ for one hour.

\section{Thermal Annealing}

Directly after the drying, calcinations of the sol-gel films were achieved by rapid thermal annealing (RTA) for $10 \mathrm{~min}$ using a vented oven pre-heated to temperatures between 300 and $600^{\circ} \mathrm{C}$ ). 


\section{Laser Treatment}

The films dried at $80^{\circ} \mathrm{C}$ were shipped from Fraunhofer ISC Würzburg to $\mathrm{LZH}$ Hanover where laser treatment was performed. $\mathrm{A} \mathrm{CO}_{2}$ laser with the wavelength of 10,6 $\mu \mathrm{m}$ (Firestar ti-60, Synrad, Inc.) with a maximum power of $35 \mathrm{~W}$ was used. The quasicontinuous mode operated with a repetition rate of $10 \mathrm{kHz}$. The beam with a diameter of approximately $200 \mu \mathrm{m}$ was focused on the samples by a galvanometer scanner and a $\mathrm{f}$-theta lens with a focal length of $324 \mathrm{~mm}$. Feed rates ranging from $500 \mathrm{~mm} / \mathrm{s}$ to 3000 $\mathrm{mm} / \mathrm{s}$ and a hatch of $200 \mu \mathrm{m}$ between the laser lines were applied. Using these parameters the laser power density was varied between $64 \mathrm{~W} / \mathrm{mm}^{2}$ and $605 \mathrm{~W} / \mathrm{mm}^{2}$ by varying the duty cycle.

\section{Material Characterization}

Reflection curves were measured with a UV-Vis-spectrometer (Shimadzu UV-3100, Kyoto, Japan) in the range of $300 \mathrm{~nm}-1700 \mathrm{~nm}$. Analysis of the single layers was achieved using the Fresnel equations for vertical incidence and the interference law. So refractive index and layer thickness could be calculated by regarding the evaluable extremes of reflection. Details about this technique can be found in [28].

The films were characterized by X-ray diffractometry (XRD; Empyrean, Malvern Panalytical Ltd, United Kingdom) with regard to phase development. Grazing incidence X-ray diffractometry was performed at an incidence angle of $1^{\circ}$. Crystallite sizes were calculated using the Scherrer equation.

For microstructural analysis, scanning electron microscopy (SEM), (Supra 55VP, Carl Zeiss AG, Oberkochen, Germany) was used. Some samples were mechanically fractured in order to take images of cross-sections. All specimen were sputtered with platinum prior to the examination.

\section{Results and Discussion}

Thin films in $\mathrm{ZrO}_{2}$ composition were deposited on borosilicate glass substrates by dip coating. After thermal annealing their thickness and refractive index was measured. From Fig. 1 it can be seen that up to $450^{\circ}$ a steady consolidation from $350 \mathrm{~nm}$ to $125 \mathrm{~nm}$ is induced, up to $600^{\circ} \mathrm{C}$ a constant level is maintained. In parallel the refractive index of the film rises from 1,55 to 1,95 as the annealing temperature is increased.

In Fig. $1 \mathrm{~b}$ the SEM cross-sectional view of a $\mathrm{ZrO}_{2}$ coating that had been thermally annealed at $600^{\circ} \mathrm{C}$ is given. The granular microstructure is very similar to those of its alumina [3] and titania [27, 29] counterparts. Obviously, despite their different compositions and crystallinity sol-gel processing of soluble precursor powders results in comparable textural film features.

With a constant feed rate of $500 \mathrm{~mm} / \mathrm{s}$ the laser power density was varied for the irradiation of $\mathrm{ZrO}_{2}$ films that only had undergone drying at $80^{\circ} \mathrm{C}$. In Fig. 2a the resulting film thickness is given along with the values for the parallel thermal treatment experiments. The course of the respective data can well be correlated with each other: For a laser power density of $65 \mathrm{~W} / \mathrm{mm}^{2}$ the shrinkage is similar to samples that only had been dried at $80^{\circ} \mathrm{C}$. For $415 \mathrm{~W} / \mathrm{mm}^{2}$ a densification equal to thermal annealing at 

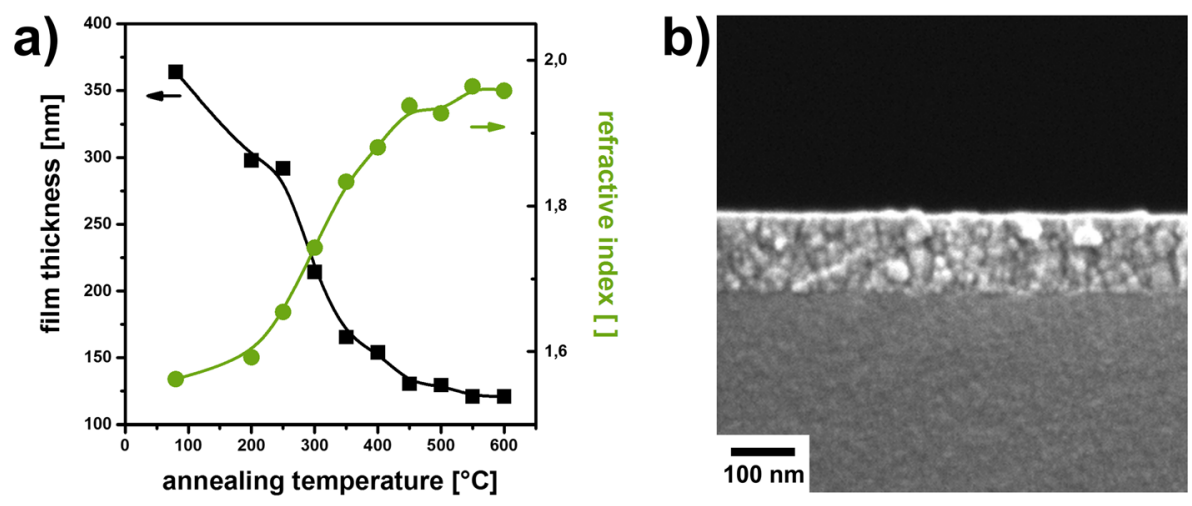

Fig. 1 Film thickness and refractive index of $\mathrm{ZrO}_{2}$ films after thermal annealing (a) and SEM cross-sectional view of sample annealed at $600^{\circ} \mathrm{C}(\mathbf{b})$. See text for details

$600^{\circ} \mathrm{C}$ is observed. For the evaluation of the refractive index (Fig. 2b) a similar good correspondence between the two experimental series can be seen: Values of 1,95 are measured for a laser power density of $415 \mathrm{~W} / \mathrm{mm}^{2}$ corresponding to annealing temperatures of 500 to $600^{\circ} \mathrm{C}$.

It has to be emphasized that the laser irradiation in our study is done on as-dried solgel coatings and the removal of residual organics as well as densification/crystallization is done in a single irradiation step. In contrast to that most of the previous reports in the literature perform laser sintering on coatings that had experienced pre-treatment in a furnace at temperatures between 300 and $500^{\circ} \mathrm{C}[7,10,15,17,19,20,25,26]$.

$\mathrm{X}$-ray diffraction (XRD) experiments were performed on the films in order to determine the crystal phases present. After furnace treatment (Fig. 3a) up to $400^{\circ} \mathrm{C}$ the coatings remain amorphous, at $450^{\circ} \mathrm{C}$ first diffraction pattern corresponding to the tetragonal phase of $\mathrm{ZrO}_{2}$ become apparent. At $500^{\circ} \mathrm{C}$ the peak intensity increases, above $550^{\circ} \mathrm{C}$ a saturation is observed. No monoclinic $\mathrm{ZrO}_{2}$ is observed which corresponds to other sol-gel derived
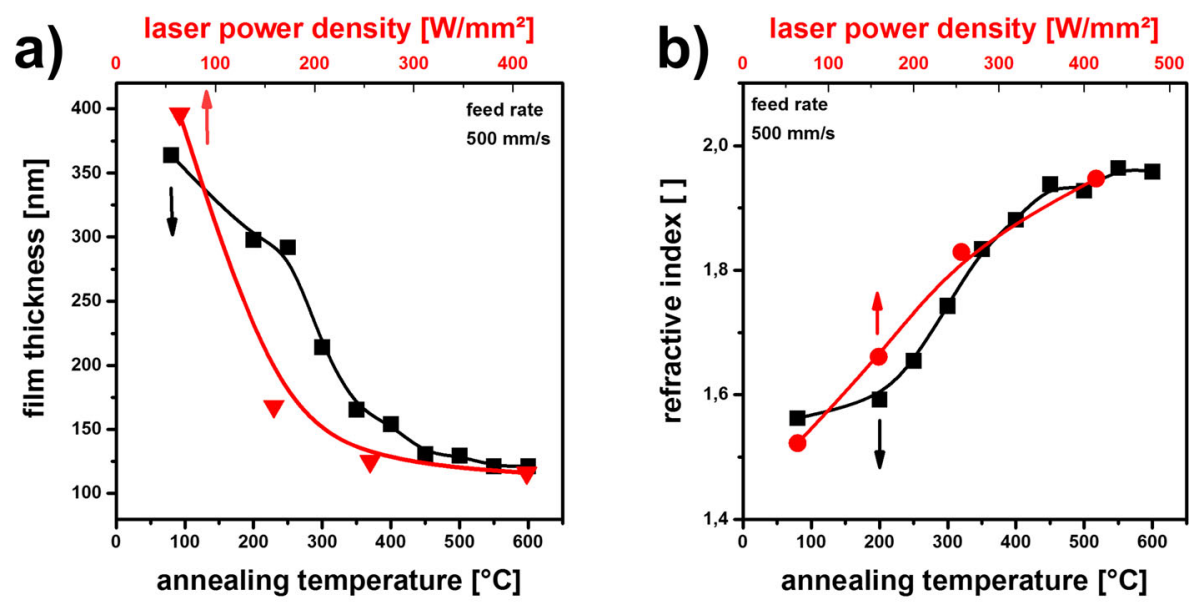

Fig. 2 Thickness (a) and refractive index (b) of $\mathrm{ZrO}_{2}$ films that had undergone thermal annealing (black) and laser treatment (red). The feed rate was fixed at $500 \mathrm{~mm} / \mathrm{s}$ whereas the laser power density was varied 

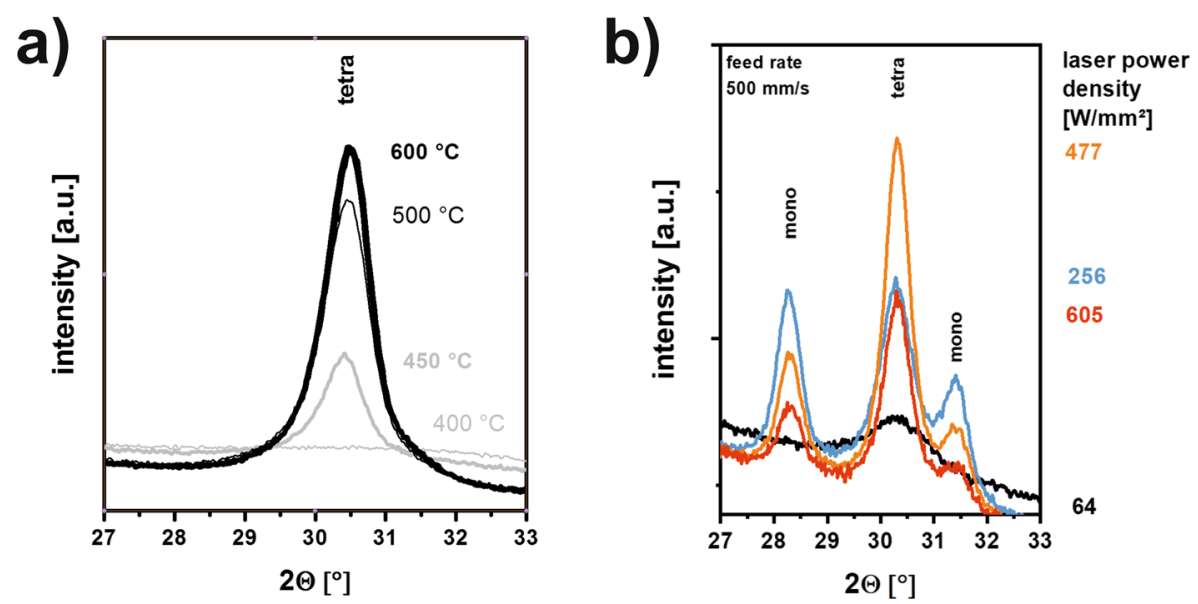

Fig. 3 X-ray diffraction pattern of $\mathrm{ZrO}_{2}$ films after thermal annealing (a) and samples that had undergone $\mathrm{CO}_{2}$ laser treatment (b) with the feed rate fixed at $500 \mathrm{~mm} / \mathrm{s}$ and laser power rates as indicated

coatings after annealing at $500^{\circ} \mathrm{C}[30]$. In contrast to that report, however, our films remain free from cracks throughout thermal processing.

Laser treatment at $64 \mathrm{~W} / \mathrm{mm}^{2}$ results in the first appearance of tetragonal $\mathrm{ZrO}_{2}($ Fig. $3 \mathrm{~b}$ ), above that laser power density this phase coexists with monoclinic $\mathrm{ZrO}_{2}$. The appearance of this thermodynamically more stable modification takes place in sol-gel derived films at temperatures exceeding $600^{\circ} \mathrm{C}[31,32]$. It therefore can be concluded that the local temperatures during laser sintering well exceed $600^{\circ} \mathrm{C}$ as suggested by theoretical simulations $[19,23]$ where surface temperatures exceeding $1000^{\circ} \mathrm{C}$ were calculated. In addition, it has been found that the crystallization of monoclinic $\mathrm{ZrO}_{2}$ is favored by high heating rates [33].

As an intermediate result, it has to be noted, that different crystalline phases and thus differences in microstructure result from thermal annealing and $\mathrm{CO}_{2}$ laser treatment, even though the film thickness and refractive index (Fig. 2) on first sight suggested matchable trends.

In our previous investigation on $\mathrm{TiO}_{2}$ films, a similar behavior was observed: Laser treatment resulted solely in formation of the thermodynamically stable rutile phase, whereas in conventional thermal annealing only phase-pure anatase was found [27].

It appears from Fig. $3 \mathrm{~b}$ that the peak intensity decreases when the laser power density is raised to $605 \mathrm{~W} / \mathrm{mm}^{2}$. This observation may indicate the removal of film material by ablation at high energies as previously reported [34].

The crystal sizes as calculated from the peak width of Fig. 3 by the Scherrer equation are given in Fig. 4. Thermal annealing between 500 and $600^{\circ} \mathrm{C}$ results in crystallites of tetragonal $\mathrm{ZrO}_{2}$ with sizes between $15 \mathrm{~nm}$ and $20 \mathrm{~nm}$. These diameters basically conform to the size of granular structures found in Fig. 1b. For laser annealing with power densities below $300 \mathrm{~W} / \mathrm{mm}^{2}$ tetragonal grains in the same order of magnitude are found. Above $300 \mathrm{~W} / \mathrm{mm}^{2}$ tetragonal and monoclinic $\mathrm{ZrO}_{2}$ coexist with grain sizes exceeding the values measured for films that had undergone thermal treatment. This observation supports the assumption that the local temperatures during laser irradiation significantly exceed $600^{\circ} \mathrm{C}$. 


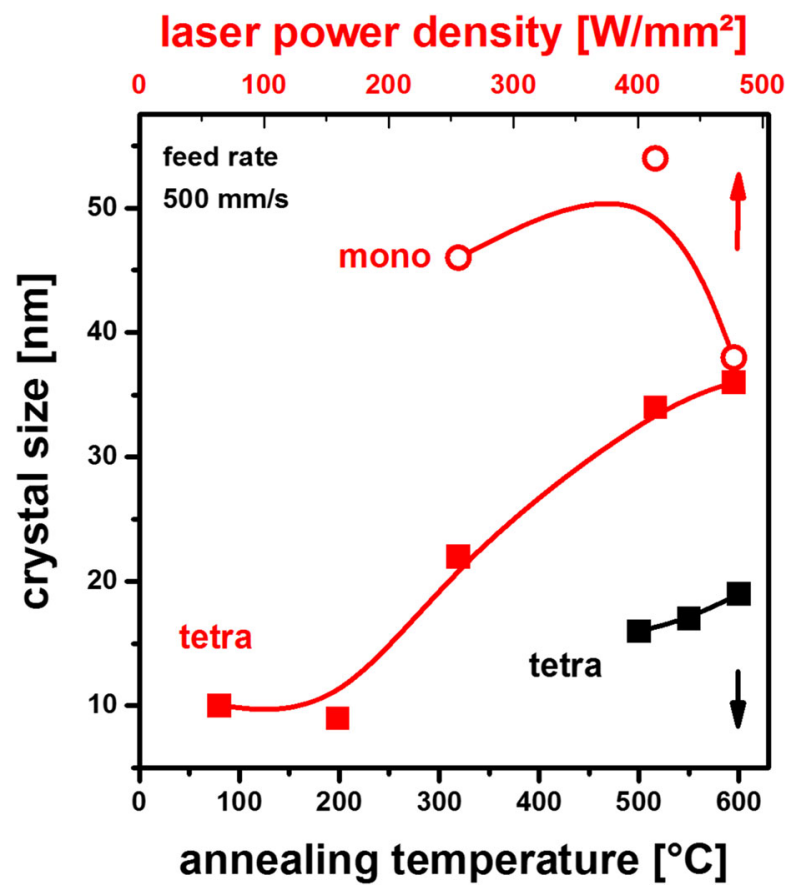

Fig. 4 Crystal size of $\mathrm{ZrO}_{2}$ films after thermal annealing (black) and samples that had undergone $\mathrm{CO}_{2}$ laser treatment (red) with different laser power density. The laser feed rate was fixed at $500 \mathrm{~mm} / \mathrm{s}$

For a given laser power density the beam feed rate determines the photon fluence, in a manner of speaking the local energy input to the substrate: The faster a given beam traverses, the smaller the power delivered to the surface.

With a power density of $414 \mathrm{~W} / \mathrm{mm}^{2}$ and a feed rate of $500 \mathrm{~mm} / \mathrm{s}$ a film densification similar to that of thermal sintering at $600^{\circ} \mathrm{C}$ was obtained (Fig. 2). With this given power output the feed rate of the laser beam was varied from $500 \mathrm{~mm} / \mathrm{s}$ to $4000 \mathrm{~mm} / \mathrm{s}$. In Fig. 5a the resulting $\mathrm{ZrO}_{2}$ film thickness is compared to that resulting from conventional furnace processing. It can be seen that the laser irradiation can precisely emulate the thermal film densification. The same applies for the refractive index of the $\mathrm{ZrO}_{2}$ coatings (Fig. 5b).

XRD phase analysis was performed on this sample series. From Fig. 6a it can be seen that a feed rate of $500 \mathrm{~mm} / \mathrm{s}$ results in a certain ratio of monoclinic to tetragonal reflex intensity, that is shifted to tetragonal $\mathrm{ZrO}_{2}$ at higher feed rates. At $1500 \mathrm{~mm} / \mathrm{s}$ the tetragonal phase is detected almost exclusively. Obviously, the energy input under these conditions does not facilitate the formation of the thermodynamically more stable monoclinic phase any more. When the feed rate is raised to $3000 \mathrm{~mm} / \mathrm{s}$, the diffraction signal corresponding to tetragonal $\mathrm{ZrO}_{2}$ is transformed to a broad hump indicating a low level of crystallinity.

Crystallite size analysis reveals that for feed rates of $500 \mathrm{~mm} / \mathrm{s}$ and $1000 \mathrm{~mm} / \mathrm{s}$ tetragonal and monoclinic grains with diameters exceeding $30 \mathrm{~nm}$ coexist. For thermal treatment between 500 and $600^{\circ} \mathrm{C}$ only tetragonal crystallites with diameters between $15 \mathrm{~nm}$ and $20 \mathrm{~nm}$ were found.

Structural uniformity is a key feature for the technical application of thin films. In Fig. 7a representative SEM image for a laser-processed $\mathrm{ZrO}_{2}$ film is given. In general, no distinctive border between adjacent laser lines (hatch $200 \mu \mathrm{m}$ ) can be distinguished. 

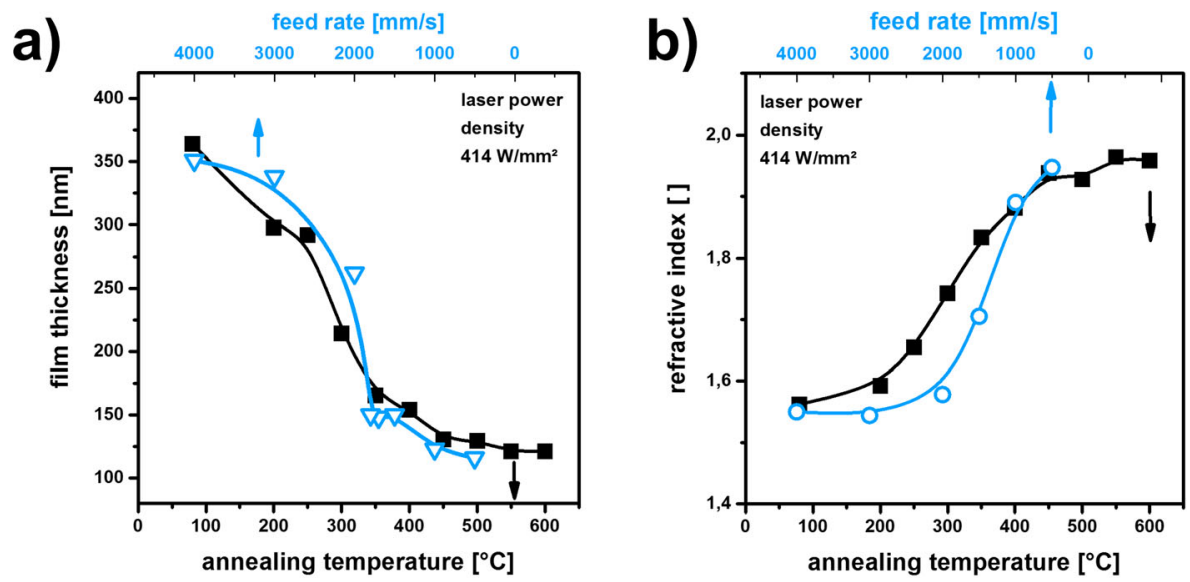

Fig. 5 Thickness (a) and refractive index (b) of $\mathrm{ZrO}_{2}$ films that had undergone thermal annealing (black) and laser treatment (blue). The laser power density was fixed at $414 \mathrm{~W} / \mathrm{mm}^{2}$ whereas the beam feed rate was varied as indicated

Within the beam center, some defects are located inside a zone of $70 \mu \mathrm{m}$ width. The crosssectional view reveals that in this region the $\mathrm{ZrO}_{2}$ film spans bubbles that extend into the substrate. The defects obviously result from partial flaking of such $\mathrm{ZrO}_{2}$ film domes. This observation suggests that the glass substrate is substantially liquefied by the high temperatures that is induced by laser processing. The bubbles are presumably generated by gaseous products that result during the pyrolysis of the sol-gel film. Outside the central defective zone, however, the $\mathrm{ZrO}_{2}$ film appears homogeneous and uniform similar to samples that have been thermally annealed (Fig. 1b).

Some similar features have been observed for laser-treated $\mathrm{TiO}_{2}$ films previously studied [27]. In contrast to that report, however, no evidence for partial $\mathrm{ZrO}_{2}$ removal

a)

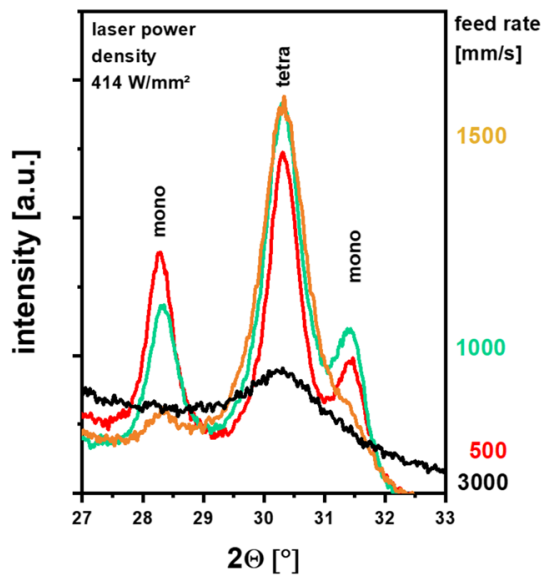

b)

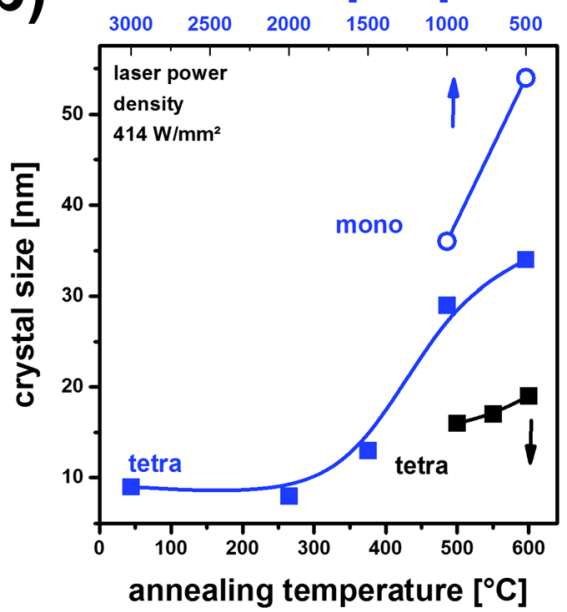

Fig. 6 X-ray diffraction pattern of $\mathrm{ZrO}_{2}$ films treated with a laser power density fixed at $414 \mathrm{~W} / \mathrm{mm}^{2}$ and a beam feed rate varied as indicated (a). In (b) the resulting crystal sizes (blue) are compared to values observed after thermal annealing (black) 


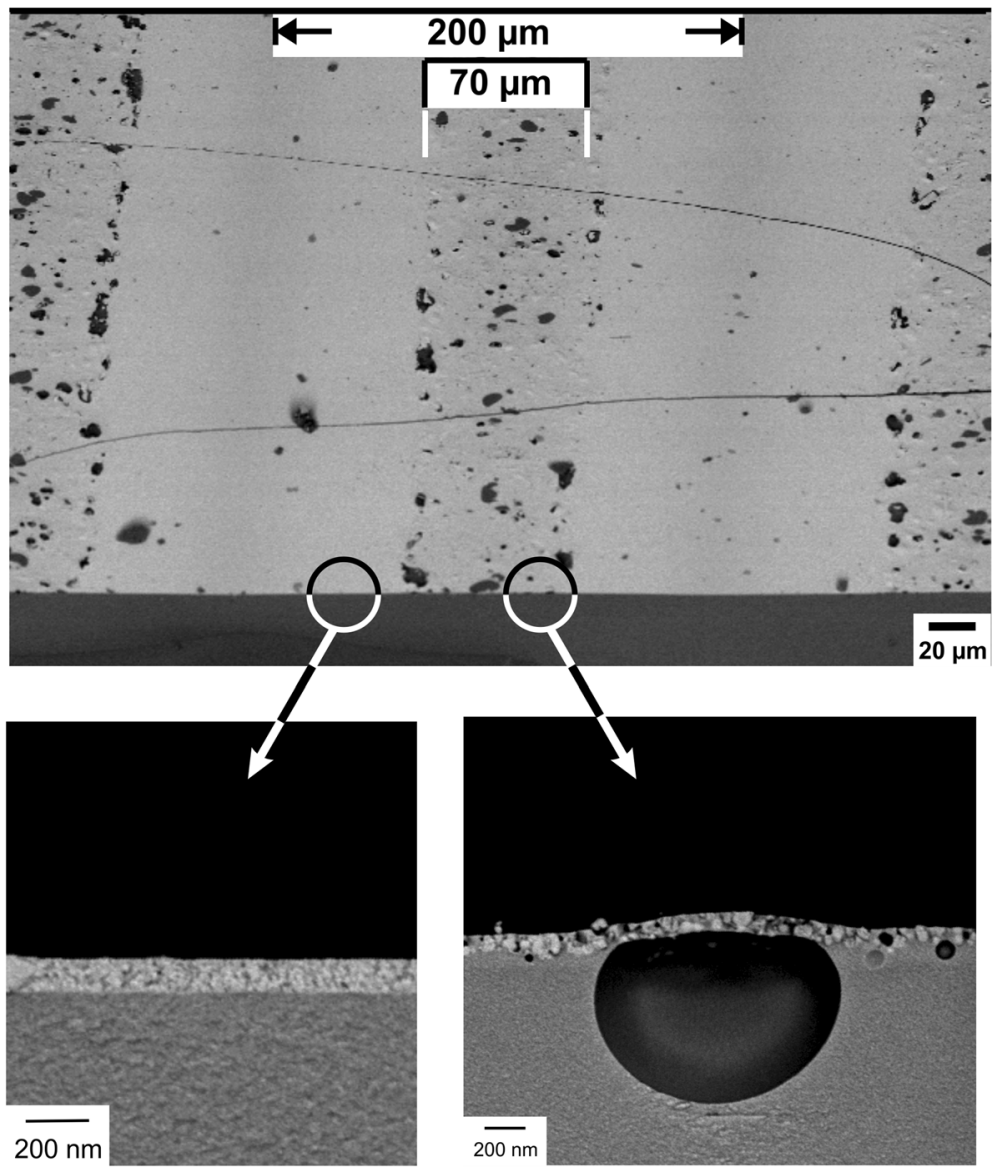

Fig. 7 SEM images of $\mathrm{ZrO}_{2}$ film after $\mathrm{CO}_{2}$ laser treatment with $415 \mathrm{~J} / \mathrm{mm}^{2}$ and a beam feed rate of $500 \mathrm{~mm} / \mathrm{s}$. In the top a fractured specimen with a tilt angle of $45^{\circ}$ is shown, in the bottom part some representative images with a higher magnification are given

by ablation could be observed here even though identical laser parameters have been applied. In the whole the $\mathrm{ZrO}_{2}$ material seems to be more damage resistant than $\mathrm{TiO}_{2}$ [27].

\section{Conclusions}

$\mathrm{ZrO}_{2}$ sol-gel coatings can successfully be processed by conventional thermal annealing and $\mathrm{CO}_{2}$ laser treatment. Film properties such as film thickness, refractive index and grain size systematically correlate with laser power density and beam feed rate. Results indicate that laser irradiation locally induces substrate temperatures by far exceeding $600^{\circ} \mathrm{C}$ that lead to the coexistence of the monoclinic and tetragonal phase of $\mathrm{ZrO}_{2}$.

Acknowledgements This work was funded by the Federal Ministry for Economic Affairs and Energy (IGF grant 19454N project "LASIP”). The authors thank Laserzentrum Hannover (LZH) for the laser processing of the sol-gel films. 
Funding Information Open Access funding provided by Projekt DEAL.

\section{Compliance with Ethical Standards}

Conflict of Interest The authors declare that they have no competing interests.

Open Access This article is licensed under a Creative Commons Attribution 4.0 International License, which permits use, sharing, adaptation, distribution and reproduction in any medium or format, as long as you give appropriate credit to the original author(s) and the source, provide a link to the Creative Commons licence, and indicate if changes were made. The images or other third party material in this article are included in the article's Creative Commons licence, unless indicated otherwise in a credit line to the material. If material is not included in the article's Creative Commons licence and your intended use is not permitted by statutory regulation or exceeds the permitted use, you will need to obtain permission directly from the copyright holder. To view a copy of this licence, visit http://creativecommons.org/licenses/by/4.0/.

\section{References}

1. Chemical solution deposition of functional oxide thin film. In: Schneller, T., Waser, R., Kosec, M., Payne, D. (eds.) Springer, Wien (2013)

2. Handbook of Sol-Gel Science and Technology. In: Klein, L. et al. (eds.) Springer International Publishing, Switzerland (2016)

3. Müller, K., Hegmann, J., Jahn, R., Löbmann, P.: Adjustable refractive index of titania-alumina thin films prepared from soluble precursor powders. J. Sol-Gel. Sci. Technol. 77(1), 69-77 (2016). https://doi. org/10.1007/s10971-015-3829-7

4. Löbmann, P.: Soluble powders as precursors for $\mathrm{TiO}_{2}$ thin films. J. Sol-Gel. Sci. Technol. 33, 275-282 (2005). https://doi.org/10.1007/s10971-005-6377-8

5. Löbmann, P., Jahn, R., Seifert, S., Sporn, D.: Inorganic thin films prepared from soluble powders and their applications. J. Sol-Gel. Sci. Technol. 19, 473-477 (2000)

6. Löbmann, P., Seifert, S., Merklein, S., Sporn, D.: Lead zirconate-titanate films prepared from soluble powders. J. Sol-Gel. Sci. Technol. 13, 827-831 (1998)

7. Sandu, C.S., Teodorescu, V.S., Ghica, C., Canut, B., Blanchin, M.G., Roger, J.A., Brioude, A., Bret, T., Hoffmann, P., Garapon, C.: Densification and crystallization of $\mathrm{SnO} 2$ : Sb sol-gel films using excimer laser annealing. Appl. Surf. Sci. 208-209, 382-387 (2003). https://doi.org/10.1016/S0169-4332(02)01412-5

8. Berkani, O., Latrous, K., El Hamzaoul, H., Bouazaoul, M., Capoen, B.: UV laser irradiation-induced crystallization in titania thick film prepared using sol-gel method. JNTM 2(2), 13-17 (2012)

9. Nagase, T., Ooie, T., Sakakibara, J.: A novel approach to prepare zinc oxide films: Excimer laser irradiation of sol-gel derived precursor films. Thin Solid Films. 357, 151-158 (1999). https://doi. org/10.1016/S0040-6090(99)00645-8

10. Tsang, W.M., Wong, F.L., Fung, M.K., Chang, J.C., Lee, C.S., Lee, S.T.: Transparent conducting aluminum-doped zinc oxide thin film prepared by sol-gel process followed by laser irradiation treatment. Thin Solid Films. 517(2), 891-895 (2008). https://doi.org/10.1016/j.tsf.2008.08.157

11. Joya, Y.F., Liu, Z.: Effect of the excimer laser irradiation on sol-gel derived tungsten-titanium dioxide thin films. Appl. Phys. A. 102(1), 91-97 (2011). https://doi.org/10.1007/s00339-010-6151-9

12. Joya, Y.F., Liu, Z., Wang, Z.: Generation of silver-anatase nanocomposite by excimer laser-assisted processing. AIP Adv. 2(032171), 1-8 (2012). https://doi.org/10.1063/1.4754284

13. Tsay, C.-Y., Huang, T.-T.: Characterization of low-temperature solution-processed indium-zinc oxide semiconductor thin films by $\mathrm{KrF}$ excimer laser annealing. Ceram. Int. 40(6), 8287-8292 (2014). https://doi.org/10.1016/j.ceramint.2014.01.030

14. Dellis, S., Isakov, I., Kalfagiannis, N., Tetzner, K., Anthopoulos, T.D., Koutsogeorgis, D.C.: Rapid laserinduced photochmeical conversion of sol-gel precursors to $\mathrm{In}_{2} \mathrm{O}_{3}$ layers and their application in thin-film transistors. J. Mater. Chem. C. 5, 3673-3677 (2017). https://doi.org/10.1039/c7tc00169

15. Su Kim, M., Kim, S., Leem, J.-Y.: Laser-assisted sol-gel growth and characteristics of ZnO thin films. Appl. Phys. Lett. 100, 252108 (2012). https://doi.org/10.1063/1.4729944 
16. Langlade, C., Vannes, B., Sarnet, T., Autric, M.: Characterization of titanium oxide films with Magneli structure elaborated by sol-gel route. Appl. Surf. Sci. 186, 145-149 (2002). https://doi.org/10.1016 /S0169-4332(01)00642-0

17. Al-Asedy, H.J., Al-Khafaji, S.A., Bakhtiar, H., Bidin, N.: Properties of Al- and Ga-doped thin zinc oxide films treated with UV laser radiation. Appl. Phys. A. 124(3), 223 (2018). https://doi.org/10.1007/s00339018-1619-0

18. Pütz, J., Ganz, D., Gasparo, G., Aergeter, M.A.: Influence of the Heating Rate on the Microstructure and on Macroscopic Properties of Sol-Gel $\mathrm{SnO}_{2}$ : Sb Coatings. J. Sol-Gel. Sci. Technol. 13, 1005-1010 (1998)

19. Baber, J., Raether, F.: Production of oxide ceramic coatings on glass by laser sintering. Glass Sci. Technol. 73(7), 211-214 (2000)

20. Jiwei, Z., Liangying, Z., Xi, Y., Hofgson, S.N.B.: Characteristics of laser-densified and conventionally heat treated sol-gel derived silica-titania films. Surf. Coat. Technol. 138, 135-140 (2001). https://doi. org/10.1016/S0257-8972(00)01158-0

21. Chou, C.-C., Tsai, S.-D., Tu, W.-H., Yeh-Liu, Y.-E., Tsai, H.-L.: Low-temperature processing of sol-gel derived $\mathrm{Pb}(\mathrm{Zr}, \mathrm{Ti}) \mathrm{O}_{3}$ thick films using $\mathrm{CO}_{2}$ laser annealing. J. Sol-Gel. Sci. Technol. 42(3), 315-322 (2007). https://doi.org/10.1007/s10971-007-0768-y

22. Buerhop, C., Blumenthal, B., Weissmann, R., Lutz, N., Biermann, S.: Glass surface treatment with excimer and $\mathrm{CO}_{2}$ lasers. Appl. Surf. Sci. 46, 430-434 (1990). https://doi.org/10.1016/0169-4332(90)90184-2

23. Wang, X., Jiao, J., Lu, H.: Temperature and stress prediction for $\mathrm{CO}_{2}$ laser heating glass plate, Gmunden, Austria, pp. 1-6. SPIE, Bellingham (2006). https://doi.org/10.1117/12.739389

24. Chung, C.K., Chuang, K.P., Cheng, S.Y., Lin, S.L., Hsie, K.Y.: Effect of solution contents on the evolution of microstructure and photoluminescence of laser-annealed rutile $\mathrm{TiO}_{2}$ thin films. J. Alloys Compd. 574, 83-87 (2013). https://doi.org/10.1016/j.jallcom.2013.04.045

25. Knite, M., Mezinskis, G., Shebanovs, L., Pedaja, I., Sternbergs, A.: CO2 laser-induced structure changes in lead zirconate titanate $\mathrm{Pb}\left(\mathrm{Zr}_{0.58} \mathrm{Ti}_{0.42}\right) \mathrm{O}_{3}$ sol-gel films, Appl. Surf. Sci. 208-209, 378-381 (2003). https://doi.org/10.1016/S0169-4332(02)01408-3

26. Medina-Valtierra, J., Frausto-Reyes, C., Ortiz-Morales, M.: Phase transformation in semi-transparent TiO2 films irradiated with $\mathrm{CO}_{2}$ laser. Mater. Lett. 66(1), 172-175 (2012). https://doi.org/10.1016/j. matlet.2011.08.076

27. Wesang, K., Hohnholz, A., Jahn, R., Steenhusen, S., Löbmann, P.: Systematic Comparison of Thermal Annealing and Laser Treatment of $\mathrm{TiO}_{2}$ Thin Films Prepared by Sol-Gel Processing. Lasers in Manufacturing and Materials Processing. 6, 387-397 (2019). https://doi.org/10.1007/s40516-019-00101-2

28. Schmitt, A., Bittner, A., Jahn, R., Löbmann, P.: Characterization of stacked sol-gel films: Comparison of results derived from scanning electron microscopy, UV-Vis spectroscopy and ellipsometric porosimetry. ThinSolidFilms 520, 1880-1884 (2012). https://doi.org/10.1016/j.tsf.2011.09.021

29. Bittner, A., Jahn, R., Löbmann, P.: $\mathrm{TiO}_{2}$ thin films on soda-lime and borosilicate glass prepared by solgel processing: Influence of the substrates. J. Sol-Gel. Sci. Technol. 58(2), 400-406 (2011). https://doi. org/10.1007/s10971-011-2406-y

30. Jothi, S., Prithivikumaran, N., Jeyakumaran, N.: Optical parameter determination of $\mathrm{ZrO} 2$ thin films prepared by sol gel dip coating. International Journal of ChemTech Research 6, 5342-5346 (2014)

31. Li, H., Liang, K., Gu, S., Xiao, G.: Oriented nano-structured $\mathrm{ZrO}_{2}$ thin films on fused quartz substrate by sol-gel process. Journal of Materials Science Letters. 20, 1301-1303 (2001). https://doi.org/10.1023 /A:1010938215228

32. Shimizu, H., Konagai, S., Ikeda, M., Nishide, T.: Characterization of Sol-Gel Derived and Crystallized $\mathrm{ZrO}_{2}$ Thin Films. Jpn. J. Appl. Phys. 48, 101101 (2009). https://doi.org/10.1143/JJAP.48.101101

33. Kogler, M., Köck, E., Vanicek, S., Schmidmair, D., Götsch, T., Stoöger-Pollach, M., Hejny, C., Klötzer, B., Penner, S.: Enhanced Kinetic Stability of Pure and Y-Doped Tetragonal $\mathrm{ZrO}_{2}$. Inorg.Chem. 53, 13247-13257 (2014). https://doi.org/10.1021/ic502623t

34. Hawelka, D., Stollenwerk, J., Pirch, N., Wissenbach, K., Loosen, P.: Improving surface properties by laser-based drying, gelation, and densification of printed sol-gel coatings. J. Coat. Technol. Res. 11(1), 3-10 (2014). https://doi.org/10.1007/s11998-013-9516-0

Publisher's Note Springer Nature remains neutral with regard to jurisdictional claims in published maps and institutional affiliations. 